\title{
Plano Municipal de Educação: elaboração, acompanhamento e avaliação no contexto do PAR
}

\author{
Municipal Educational Plan: preparation, monitoring and evaluation in the PAR \\ context \\ Plan Municipal de Educación: elaboración, seguimiento y evaluación en el \\ contexto del PAR \\ ANTÔNIO CABRAL NETO \\ ALDA MARIA DUARTE ARAUJO CASTRO \\ LUCIANE TERRA DOS SANTOS GARCIA
}

\begin{abstract}
Resumo: O artigo discute o papel dos Planos Municipais de Educação (PME) na organização do Sistema Nacional de Educação (SNE). Considera o Plano de Ações Articuladas (PAR) em municípios norte-rio-grandenses, na dimensão da gestão educacional. Utilizaram-se como procedimentos a análise documental e a revisão de literatura. Os resultados evidenciam que o PAR define a priori, o que deve ser executado pelo município, fragilizando a sua autonomia e a gestão democrática, mas vem contribuindo para consolidar práticas de planejamento. Em Mossoró e Natal, o PAR constituiu-se em referencial para o acompanhamento e avaliação dos PME já existentes, contribuindo, assim, para dinamização da construção do SNE.
\end{abstract}

Palavras-chave: PAR; gestão educacional; planos municipais.

\begin{abstract}
The paper discusses the role of the Municipal Educational Plans (PME) in the organization of the National System of Education (SNE). Considers the Articulated Action Plan (PAR) in Rio Grande do Norte municipalities related to the educational management dimension. Were used as procedures the documental analysis and literature review were used. The results show that the PAR defines, a priori, what should be executed by the municipality, weakening their autonomy and democratic management, although it is contributing to consolidate planning practices. In Mossoro and Natal, the PAR has constituted in a reference for the monitoring and evaluation of existing SMEs, thus contributing to boosting the construction of the SNE.
\end{abstract}

Keywords: PAR; educational management; municipal plans.

Resumen: El artículo discute el papel de los Planos Municipales de Educación (PME) en la organización del Sistema Nacional de Educación (SNE). Considera el Plan de Acciones Articuladas (PAR) en municipios norteriograndenses, en la dimensión de la gestión educacional. Se ha utilizado como procedimiento el análisis documental y la revisión de literatura. Los resultados evidencian que el PAR define a priori, lo que debe ser ejecutado por el municipio, fragilizando su autonomía y la gestión democrática, pero viene contribuyendo para consolidar prácticas de planificación. En Mossoró y Natal, el PAR se ha constituido 
en referencia para el seguimiento y evaluación de los PME ya existentes, contribuyendo, de esa forma, para la dinamización de la construcción del SNE

Palabras clave: PAR; gestión educacional; planos municipales.

\section{INTRODUÇÃO}

Este artigo tem por objetivo desenvolver uma reflexão circunstanciada sobre o papel dos Planos Municipais de Educação (PME) na constituição do Sistema Nacional de Educação (SNE). Toma como referência o Programa de Ações Articuladas (PAR) em municípios norte-rio-grandenses, especificamente no que se refere à dimensão da gestão educacional e à sua orientação para a elaboração dos Planos Municipais de Educação (PME), visando a instituir a gestão democrática nos municípios.Trata-se de um recorte da pesquisa realizada em rede denominada Avaliação do Plano de Ações Articuladas: um estudo nos municípios do Rio Grande do Norte, Pará e Minas Gerais, no período de 2007 a 2011, financiado pelo programa Observatório da Educação/Capes.

O artigo está organizado em três seções: a primeira discute, de forma sintética,a contribuição dos PMEpara a construção do SNE,considerado como estratégia fundamental para consolidar o regime de colaboração entre os entes federados. A segunda seção contempla uma análise do PAR, situando-o como instrumento de planejamento governamental, indutor da elaboração e execução de PME.A terceira parte analisa como o PAR influenciou na consolidação e/ou reelaboração dos planos municipais de educação em municípios do Estado do Rio Grande do Norte.

\section{SISTEMA NACIONAL DE EDUCAÇÃO E A SUA RELAÇÃO COM PLANOS MUNICIPAIS DE EDUCAÇÃO}

O tema que trata da necessidade de se construir um sistema nacional de educação vem sendo colocado reiteradamente na agenda do debate educacional no país. Várias iniciativas foram tomadas, mas persiste ainda a lacuna no que concerne ao essencial, que é formatar, de maneira orgânica, o sistema no qual fiquem evidenciadas as responsabilidades dos entes federados na tarefa inadiável de ofertar à população uma educação de qualidade socialmente referenciada. A lei que aprovou o Plano Nacional de Educação (Lei no 13.005, de 25 de junho de 2014) determina, em seu art. 13, que o poder público deverá instituir, em lei específica, contados dois anos da publicação da referidalei, "o Sistema Nacional de Educação, responsável pela articulação entre os sistemas de ensino, em regime de 
colaboração, para efetivação das diretrizes, metas e estratégias do Plano Nacional de Educação" (BRASIL, 2014).

A criação do sistema se constitui em medida necessária para a conformação de um mecanismo para viabilizar as metas do PNE 2014/2024,considerando que tornaria claras as competências e as responsabilidades dos entes federados no que concerne ao campo da educação. O regime de colaboração se constituiria,então, em mecanismo essencial para a viabilização das metas do PNE, pondo em evidência, portanto, que o sucesso do plano estaria na capacidade de articulação entre os entes federados.

Nesse sentido, o art. $7^{\circ}$ da Lei n ${ }^{\circ} 13.005$, de 25 de junho de 2014, determina que "A União, os Estados, o Distrito Federal e os Municípios atuarão em regime de colaboração, visando ao alcance das metas e à implementação das estratégias objeto deste Plano (BRASIL, 2014). No \ $2^{\circ}$ desse artigo, fica exarado que "As estratégias definidas no Anexo desta Lei não elidem a adoção de medidas adicionais em âmbito local ou de instrumentos jurídicos que formalizem a cooperação entre os entes federados, podendo ser complementadas por mecanismos nacionais e locais de coordenação e colaboração recíproca" (Idem).

Reafirmando a importância de se estabelecer o regime de colaboração, of $5^{\circ}$ do artigo $7^{\circ}$ determina que "Será criada uma instância permanente de negociação e cooperação entre a União, os Estados, o Distrito Federal e os Municípios" e o $\int 6^{\circ}$, do mesmo artigo, prevê que o "fortalecimento do regime de colaboração entre os Estados e respectivos Municípios incluirá a instituição de instâncias permanentes de negociação, cooperação e pactuação em cada Estado" (Idem).

O Plano Nacional de Educação deve, em princípio, criar as condições necessárias para assegurar o direito à educação e induzir os entes subnacionais para elaborar os planos estaduais, distritais e municipais com o mesmo intuito. Esses planos desempenham papel substancial na configuração do SNE, que exige, ao mesmo tempo, firme coordenação nacional, sem, contudo, desconsiderar a autonomia relativa dos entes federados na formulação da política educacional. Nesse sentido, como argumenta Cabral Neto (2014), o Plano Nacional de Educação deve garantir, ao mesmo tempo, a unidade nacional e as peculiaridades regionais e locais; deveser capaz, sobretudo, de articular democraticamente os vários níveis de governo para procederàs mudanças necessárias nos sistemas educacionais.

$\mathrm{Na}$ lei que aprova o PNE fica instituído o imperativo legal de que os entes federados subnacionais elaborem seus planos de educação, reafirmando, desse modo, a importância desse mecanismo de planejamento para a formatação do SNE. Nesse sentido, o art. $8^{\circ}$ da Lei no 13.005, de 25 de junho de 2014 
especifica que "Os Estados, o Distrito Federal e os Municípios deverão elaborar seus correspondentes planos de educação, ou adequar os planos já aprovados em lei, em consonância com as diretrizes, metas e estratégias previstas neste PNE, no prazo de um ano contado da publicação desta Lei” (BRASIL, 2014). No que concerne à elaboração dos planos o parágrafo $2^{\circ}$ desse artigo determina que "Os processos de elaboração e adequação dos planos de educação dos Estados, do Distrito Federal e dos Municípios [...], serão realizados com ampla participação de representantes da comunidade educacional e da sociedade civil" (BRASIL, 2014).

Fica evidente que os planos estaduais e municipais de educação se tornam peças importantes no processo de configuração do sistema nacional de educação, na medida em que se constituem em elos essenciais na viabilização do regime de colaboração e, por conseguinte, na materialização das metas do PNE. Isso porque um Plano Nacional de Educação na medida em que estabelece as diretrizes para a elaboração dos planos estaduais e municipais de educação propicia as condições favoráveis para a edificação de políticas com maior possibilidade de articulação federativa. A efetiva articulação entre os planos nacional, estaduais e municipais de educação é fundamental para a efetivação do SNE. Essa dinâmica entendida como

\footnotetext{
Ação de planejamento decenal articulado, deverá reforçar a concepção de que as metas nacionais se concretizam em cada ponto do país onde está uma pessoa a quem o direito deve ser garantido. Essa concepção deverá evitar a transposição mecânica das metas nacionais para os planos subnacionais, dada a necessidade de considerar as diferenças e desigualdades regionais. Além disso, [...]é importante articular de forma definitiva o planejamento educacional decenal a outros instrumentos de planejamento de governos, tais como os Planos Plurianuais, os Planos de Ações Articuladas (Lei 12.695/2012) e outros mecanismos de financiamento. Tais previsões de obrigatoriedade darão sustentação ao disposto no Artigo 214 da Constituição, concretizando o papel articulador do Plano Nacional de Educação (MEC/SASE, 2015, p. 08).
}

O documento reafirma a necessidade inadiável de se construirem acordos pactuados nos quais fiquem estabelecidas as regras federativas para a construção e organização do SNE, delineando, claramente, as condições para a efetivação das ações e, sobretudo, os responsáveis pelas deliberações e execução das decisões tomadas. OSNEtem como principal articulador o PNE, que fornece as bases para sua criação em regime de colaboração, definindo as atribuições dos entes federados com vistas à garantia da efetiva educação de qualidade para todos.

Saviani (2010) defende a necessidade de se instituir um sistema nacional de educação que não dependa das adesões autônomas e "a posteriori” de estados e municípios. A decisão de aderir ao sistema nacional "deve ser resultante da participação efetiva desses entes na sua concepção, o que criará as condições 
institucionais para que todos se submetam às suas regras pactuadas coletivamente" (SAVIANI, 2010, p. 16).

Para a organização do SNE, como argumenta Cury (2013), torna-se necessária a formulação de um pacto federativo que, ao ser concebido em bases democráticas, crie as condições institucionais para a edificação de consensos sobre temas como: infraestrutura, gestão, avaliação, currículo, financiamento, formação e valorização dos profissionais da educação, indispensáveis para a constituição do sistema e para seu funcionamento.

Desse modo, o SNE deve constituir-se em mecanismo articulador do regime de colaboração no âmbito do pacto federativo, que prevê a unidade nacional, respeitando a autonomia dos entes federados, tal como consta na Constituição Federal de 1988 (BRASIL 2010). No Estado Federativo, vigora, em princípio, a colaboração e o compartilhamento no processo de tomada de decisão entre a União e os demais entes federados; cada um dos níveis de governo, todavia, mantém sua autonomia.

A organização do SNE requer, necessariamente, uma dinâmica que implique a formulação de regras pactuadas nas quais fiquem evidenciados, claramente, os papéis dos entes federados de modo que seja assegurado o exercício da autonomia dos vários níveis de governo na definição de políticas educacionais, sem, contudo, perder de vista a coordenação nacional. Nesses termos, os planos estaduais e municipais de educação devem funcionar, também, como espaço de formulação de políticas que atendam às necessidades regionais e locais, o que materializaria o espaço de autonomia dos entes subnacionais.

\section{O PAR COMO INSTRUMENTO DE PLANEJAMENTO GOVERNAMENTAL: REPERCUSSÕES NOS PLANOS MUNICIPAIS DE EDUCAÇÃO}

As políticas governamentais se efetivam por meio de uma ação planejada que articula as diversas esferas do governo, evitando ações sobrepostas, descontínuas e fragmentadas. A partir dos anos 2000, o planejamento governamental, na área educacional, tem assumido centralidade no âmbito das políticas públicas. Nesse contexto, o processo de tomada de decisão e a organização dos meios necessários para alcançar fins educacionais integram-se às estratégias implementadas para incrementar o crescimento econômico do país. Segundo Fonseca (2003), o planejamento é afetado por determinantes conjunturais oriundos da economia bem como do mercado interno e externo; por interferências de setores da sociedade, de grupos sociais que, por força do seu poderio econômico e político, 
agem junto ao estado como formadores de opinião, e depende ainda da vontade política dos entes federados. Nas últimas décadas, segundo Cardoso Jr (2011),

\begin{abstract}
A função do planejamento foi sendo esvaziada de conteúdo político estratégico, robustecida de ingredientes técnico-operacionais e de controle e comando físicofinanceiros, em torno de ações difusas pelos diversos níveis e instâncias de governo, cujo sentido de conjunto e movimento, se estes o têm, mesmo setorialmente considerado, não é fácil nem fácil de identificar (p. 21).
\end{abstract}

Nessa mudança do papel estratégico do planejamento, este começa a ser pensado para curto e médio prazo, materializado pelos Planos Plurianuais (PPA). Esse instrumento de planejamento define as prioridades do governo por um período de quatro anos e deve contemplar as diretrizes, os objetivos e as metas da administração pública federal para as despesas de capital bem como outras delas decorrentes e para as relativas aos programas de duração continuada. Consta, nesse tipo de planejamento, o princípio de que deve se reduzir o horizonte do planejamento para o curto/médio prazo, condicionando-o, simultaneamente, ao orçamento prévio disponível.

O PPA está previsto na Constituição Federal de 1988 (BRASIL, 2010); entretanto, estrutura-se, apenas, a partir da segunda metade de 1990. Com essa forma de planejamento, a gestão do governo, a partir do PPA 2004-2007, passou a ser organizada por programas compostos por um conjunto articulado de ações e voltados para a solução de problemas ou demandas da sociedade (BRASIL 2003). Essa tendência prevaleceu também no Plano Plurianual (2008-2011), que destaca três agendas prioritárias: Agenda Social, Plano de Desenvolvimento da Educação (PDE) e Programa de Aceleração do Crescimento (PAC). Nesse PPA, a educação é entendida como objetivo estratégico para o desenvolvimento nacional, considerando-se que a competitividade do campo econômico, a equidade social e o desempenho cidadão são amplamente impactados pela educação (BRASIL, 2007a). O governo procura, com o PDE, assegurar a melhoria da qualidade da educação representada pela conjugação dos esforços das Unidades da Federação, atuando em regime de colaboração com a participação das famílias e da comunidade.

O PDE se apresenta como plano de governo para a educação, embora alguns estudiosos, a exemplo de Saviani (2007), o considerem apenas como uma junção de mais de 40 programas e instrumentos avaliativos que contemplam a educação em todas as etapas, níveis e modalidades. A ideia consistia em integrar os programas educacionais, garantindo o vínculo entre os diferentes níveis de ensino de forma sistêmica, e, ainda, em fortalecer o regime de colaboração, 
possibilitando a gestão compartilhada entre os três níveis de governo (federal, estadual e municipal).

O PDE é o instrumento de planejamento aprovado pelo poder executivo para dinamizar o regime de colaboração. Com essa finalidade, foi aprovado o Plano de Metas Compromissos Todos pela Educação, pelo Decreto n ${ }^{\circ}$ 6.094/07, que, na Seção II, estabelece o Plano de Ações Articuladas (PAR), entendido como: “o conjunto articulado de ações, apoiado técnica ou financeiramente pelo Ministério da Educação, que visa o cumprimento das metas do Compromisso e a observância das suas diretrizes" (BRASIL, 2007b).

A normatização do PAR está materializada nas Resoluções $\mathrm{n}^{\circ}$ 29/07(BRASIL, 2007c), na no 47/07 (BRASIL, 2007d) e na no 14/12 (BRASIL, 2012)do FNDE, que estabelecem os critérios e procedimentos a serem executados pela União e pelos subgovernos nacionais visandoa operacionalizar o apoio técnico ou financeiro previstos no decreto para os subgovernos nacionais. A legislação de maior importância em termos de normatividade é a Resolução n ${ }^{\circ}$ 29/07 (BRASIL, 2007c), em virtude de conter os critérios e parâmetros para operacionalização do PAR no âmbito do Compromisso Todos pela Educação. O PAR, a partir da referida resolução, pretende promover a gestão democrática da educação e reúne indicadores que contribuem para uma análise da qualidade da educação dos municípios, por meio do diagnóstico da realidade educacional.

As ações do PAR englobam todas as dimensões constitutivas dos sistemas educacionais, tendo em vista a melhoria da qualidade da educação. Assim, contempla ações que envolvem a gestão educacional, a formação de professores e de profissionais de serviço e apoio escolar, aspráticas pedagógicas e de avaliação bem como a infraestrutura física e recursos pedagógicos. Essas quatro dimensões são consideradas indispensáveis para umaeficiente gestão da educação. De acordo com as Resoluções $n^{\circ}$ 29/07 (BRASIL, 2007c), no 47/07(BRASIL, 2007d) e $n^{\circ}$ 14/12 (BRASIL, 2012) do FNDE, as secretarias estaduais e municipais devem organizar sua gestão educacional com base nas dimensões, áreas e estratégias previstas no guia prático de ações do PAR.

No que se refere à gestão educacional, há um paradoxo que tem dificultado sua execução, visto que, ao mesmo tempo que o PAR é elaborado com uma concepção gerencial, baseada na eficiência e na produtividade do sistema educativo, estimula, por meio dos seus indicadores, a implementação e a consolidação da gestão democrática dossistemas educacionais. Essas diferentes concepções de gestão têm provocado um hibridismo na condução dos problemas educacionais, fazendo com que os gestores assumam um discurso de gestão democrática e atuem de forma gerencial, comprometendo os avanços existentes nos sistemas na implementação da gestão democrática da educação. 
Concernente à Gestão educacional,o PAR contempla cinco áreas: 1 Gestão Democrática: articulação e desenvolvimento dos sistemas de ensino; 2 - Desenvolvimento da Educação Básica: ações que visem a sua universalização, à melhoria da qualidade do ensino e da aprendizagem assegurando a equidade nas condições de acesso e permanência e conclusão na idade certa; 3 - Comunicação com a sociedade; 4 - Suficiência e estabilidade da equipe escolar; área 5 - Gestão de finanças.

Pertinente à gestão democrática-área de interesse do artigo em questão - é válido destacar a ação de criação ou consolidação dos planos municipais de educação, indispensável para a construção do Sistema Nacional de Educação. Os planos municipais de educaçãopossibilitam uma reflexão a longo, médio e curto prazo de uma determinada realidade, o estabelecimento de metas, estratégias e ações que os municípios devem alcançar tendo em vista a melhoria da Educação Básica. Com o Plano Municipal de Educação,pode-se dizer que, efetivamente, o município vai estruturar uma política pública para a área da educação. Esses planos servirão, teoricamente, para orientar os municípios na definição de metas próprias, definição de ações, de responsabilidades (do poder público e comunidade em geral) e dos recursos que devem ser aplicados para que se alcance uma educação democrática, igualitária e de qualidade, assegurando, assim, um direito básico de cidadania.

A exigência de elaboração dos PMEs não constitui uma novidade, visto que, desde o primeiro Plano Nacional de Educação (2001-2010) (BRASIL 2001), já havia a previsibilidade de que os municípios elaborassem seus planos como uma iniciativa para a instituição do Sistema Nacional de Educação. O novo PNE (2014-2024) vai além e estabelece um prazo para os municípios elaborarem seus PMEs (BRASIL, 2014).A importância do PME não reside, apenas, em garantir um direito fundamental pelo qual os municípios têm grande responsabilidade. A construção coletiva do PME e sua implementação têm o potencial de mudar a forma como os gestores e a comunidade lidam com as políticas educacionais.

No entanto, há grande distância entre o que a lei preconiza e a forma como ela é operacionalizada nos municípios brasileiros. Segundo dados do Instituto Brasileiro de Geografia e Estatística (IBGE, 2009), por ocasião da implementação do primeiro PAR, a situação dos municípios brasileiros que tinham os planos municipais aprovados era a seguinte: do total de 5.565 municípios, 56,38\% informaram a existência do Plano Municipal. A região com maior número de municípios com planos municipais é a região Sudeste com $72,66 \%$, seguida da região Centro-Oeste com 54,03\%, da região Sul, com 51,34\%, do Nordeste com $50,39 \%$ e da região Norte com 38,08\%. 
Esses números não se alteram, substancialmente, quando se considera o ano de 2011, final de vigência do primeiro PAR.De acordo com dados do (IBGE), no ano de 2011 (IBGE, 2012), dos 5.565 municípios brasileiros, apenas 60,80\% possuíam seus PMEs aprovados.Comparando-se com a situação, do ano de 2009, verifica-se que ocorreu um aumento inexpressivo (4,42\%). A região com maior número de municípios com planos municipais aprovados é a região Sudeste com $76,9 \%$, seguida da região Sul com 57,74\%, da Região Nordeste com 57,46\%, da Centro-Oeste com 47,42\% e da região Norte com 36,74\%.

A situação dos Planos Municipais constatada justifica a necessidade de uma ação indutora do PAR (2012-2014) para instituir ações de assessoramento para que os municípios possam elaborar ou reestruturar seus planos municipais, garantindo a efetiva participação de todos os implicados na educação municipal. Reafirma-se que o princípio da participação deve ser o cerne de todo o processo de construção dos PMEs. O prazo determinado no Plano Nacional de Educação2014-2024para que os municípios elaborassem os Planos de Educação, foi insuficiente para propiciar uma participação mais efetiva da sociedade civil, fragilizando, desse modo, os princípios democráticos que devem nortear esse processo.

\section{PLANO MUNICIPAL DE EDUCAÇÃO EM MUNICÍPIOS DO RN: UMA ANÁLISE A PARTIR DO PAR}

O Plano de Ações Articuladas (PAR), por sua abrangência e sistemática, pode colaborar na construção de uma cultura de planejamento educacional em muitos municípios brasileiros ou, ainda, influenciar práticas consolidadas. A elaboração do PAR inicia-se com o diagnóstico da situação educacional da rede de ensino, possibilitando traçar um perfil da realidade municipal no que concerne, entre outros aspectos, à existência, à implementação e à avaliação de planos municipais de educação em articulação com o Plano Nacional.

Considerando a importância dos dados sistematizados no diagnóstico do PAR, referentes à (re) elaboração dos Planos Municipais de Educação, analisamse as ações previstas no PAR, nos períodos 2007-2011 e 2012-2014, dos dois maiores municípios do Estado do Rio Grande do Norte: Natal e Mossoró. O primeiro, a capital do estado, localiza-se na região Leste Potiguar, enquanto o segundo, Mossoró, situa-se na região Oeste. Nos dois municípios, predomina a população urbana, e os setores que mais empregam são os de comércio e serviços, com forte heterogeneidade social e concentração de renda.

Dados do Instituto Brasileiro de Geografia e Estatística (IBGE, 2010) revelam que Natal possui o maior PIB do estado (11.997.401), seguida 
de Mossoró (3.496.776). Apesar de a renda per capita desses municípios ter aumentado consideravelmente no período de 2001 a 2010 - Mossoró (132\%) e Natal (91,54\%) (IBGE, 2010) -eles ainda apresentam grande desigualdade social. Essa desigualdade é expressa pelo índice Gini, que demonstram, conforme dados do PNUD referentes ao ano de 2010, que Natal apresentou um índice de desigualdade social de 0,61 e Mossoró de 0,52 (PNUD/BRASIL, 2013).

Os Índices de Desenvolvimento Humano (IDH dos dois municípios são considerados médios (entre 0,5 e 0,8), tendo Mossoró alcançado o índice de 0,720 e Natal 0,763. O “Atlas do Desenvolvimento Humano no Brasil 2013”, estudo divulgado pelo Programa das Nações Unidas para o Desenvolvimento (PNUD/BRASIL, 2013), mostrou que, entre os anos de 2000 e 2010, o Índice de Desenvolvimento Humano Municipal (IDHM) cresceu 14,91\% em Natal e 20,81\% em Mossoró. Em termos absolutos, a educação foi a dimensão com maior incremento, em virtude da proporção de crianças e jovens em idade escolar frequentando ou tendo concluído as diferentes etapas de ensino, bem como pela diminuição da taxa de analfabetismo da população de 18 anos ou mais.

Conforme o índice, a situação educacional dos municípios tem apresentado melhorias tanto em função de ações desenvolvidas pelas próprias redes de ensino, utilizando-se de sua autonomia relativa, quanto por meio da colaboração da União, que financia uma série de programas educacionais. No entanto, ainda há um longo percurso para a conquista do direito à qualidade da educação para todos; daí, a importância de planos educacionais que concatenem os esforços despendidos pelas diferentes esferas de poder. A exemplo do PAR, que, elaborado após seis anos da promulgação do PNE 2001-2010, pode ter tido papel crucial na indução do planejamento municipal, particularmente no que se refere à gestão educacional, na medida em que passou a ser matéria presente em todos os municípios brasileiros.

\section{O PLANEJAMENTO NOS MUNICÍPIOS DE NATAL E MOSSORÓ NO CONTEXTO DO PAR}

No que concerne à dimensão da gestão educacional, existe a preocupação de elaborar, acompanhar e monitorar os planos municipais, conforme demonstra o indicador 6 dessa dimensão do primeiro PAR (2007-2011), intitulado “[...] existência, acompanhamento e avaliação do Plano Municipal de Educação, desenvolvido com base no Plano Nacional de Educação"1. A análise desse PAR 1 Este indicador integra a dimensão da Gestão Educacional, Área 1 - "Gestão Democrática:
articulação e desenvolvimento dos sistemas de ensino". 
referente aos municípios de Natal e Mossoró evidenciava que esses municípios já haviam elaborado seus Planos Municipais de Educação. Segundo dados do Perfil dos Municípios Brasileiros, divulgados pelo IBGE (2012), de um total de 167 municípios do Rio Grande do Norte esses eram dois dos 121 que haviam elaborado seus Planos Municipais,ao final do tempo de vigência do PNE (20012010).

A análise do indicador 6 do PAR 2007-2011 de Natal e Mossoró revela que, apesar de terem cumprido a determinação do PNE então vigente (BRASIL, 2001) quanto à elaboração dos planos municipais, estes careciam de acompanhamento e reestruturação. Isso, provavelmente, esteja acontecendo por não haver ainda, no país, uma cultura de valorização do planejamento educacional em função do alcance de objetivos comuns. Autores como Bordignon (2014), Alcântara e Barão (2014), demonstram que, na história da educação brasileira, existem poucos registros de uma ação planificada em nível nacional. Ressaltam que, mesmo quando os planos são elaborados, muitas vezes, ou não se concretizam ou isso acontece parcialmente.

O município de Mossoró elaborou o Plano Municipal de Educação com vigência prevista para o período de 2004 a 2013 (MOSSORÓ, 2004) e o de Natal para o período de 2005 a 2014 (NATAL, 2005). No entanto, a situação desses municípios, registrada no PAR 2007-2011 demonstrou não haver ação sistemática de acompanhamento e avaliação das ações. O município de Natal justificava que a execução das metas do PME estava prevista no Plano Plurianual do Município (2006-2009); no entanto, não instituiu uma Comissão incumbida do acompanhamento e da avaliação do PME, composta por representantes da sociedade civil e das instituições públicas (NATAL, 2007). Essa justificativa demonstra que existia, no Município, a prática do planejamento de médio e curto prazo, mas, tal como acontecia em Mossoró, não havia acompanhamento sistemático das ações, tampouco o planejamento era marcado pela participação da sociedade civil.

Portanto, as duas redes se propuseram a reestruturar no PAR 2007-2011 seus Planos Municipais de Educação, sendo que Mossoró acrescentou que, nesse processo, consideraria os resultados da avaliação do plano anterior e incluiria representantes da sociedade civil (MOSSORÓ, 2007). Dessa forma, propôs-se desenvolver as subações Criar um conselho de acompanhamento e avaliação das metas do PME e Qualificar a equipe da SME para implementar e avaliar o Plano Municipal de Educação (MOSSORÓ, 2007). A rede municipal de Natal, por sua vez, definiu como subações: "[...] elaborar e aplicar instrumentos de acompanhamento, execução e avaliação do PNE e do PME; promover ações de acompanhamento 
e avaliação e promover a implantação do planejamento estratégico na Secretaria [...]" (NATAL, 2007, n.p).

A falta de acompanhamento e avaliação da execução do PME, nos dois municípios, bem como a inexistência de uma equipe responsável pela condução do processo confirmam a hipótese de Bordignon (2014) de que, predominantemente, em nosso país, os responsáveis pelo planejamento educacional têm compreendido a "[...] elaboração do plano como documento técnico. Tarefa concluída, missão cumprida. Registra-se pouca preocupação com o planejamento das ações para a sua implementação" (p. 47).

O acompanhamento contínuo das ações planejadas é uma necessidade para a sua realização, visto que possibilita identificar dificuldades e redefinir ações tendo em vista a superação de entraves e o avanço da consecução das propostas nele registradas. O acompanhamento contínuo fornece dados que precisam ser complementados por outros, provenientes de avaliações sistemáticas e periódicas, que possibilitam ao grupo responsável pelo processo, entre outras vantagens, aprender com as próprias ações e analisar se os encaminhamentos estão acontecendo de acordo com os prazos e nos moldes definidos.

Após quatro anos de implementação do PAR 2007-2001, os municípios procederam a uma nova avaliação do que foi alcançado no período. A análise da situação das duas redes de ensino, registrada no PAR de 2011 a 2014, tanto de Natal quanto de Mossoró (MOSSORÓ, 2011a; NATAL, 2011) apontou para a existência de avanços parciais, no que se refere à avaliação e acompanhamento do PME. Nessa edição do PAR, o indicador 1, referente à Existência, acompanhamento e avaliação do Plano Municipal de Educação (PME), desenvolvido com base no Plano Nacional de Educação, recebeu pontuação 3 nas duas redes de ensino. Atribui-se essa pontuação à situação em que

\footnotetext{
Existe o Plano Municipal de Educação (PME) e o acompanhamento e avaliação de suas metas, com a participação de professores e gestores, sem a presença de representantes da sociedade civil organizada. A avaliação não é contínua e o acompanhamento é voltado à análise de aspectos apenas quantitativos" (MOSSORÓ, 2011a, n.p.; NATAL, 2011, n.p.).
}

Em sua justificativa para a atribuição da pontuação 3, o Município de Mossoró informa que foi “[...] realizado, em 2008, a avaliação do Plano e, com base em seus resultados, vem sendo feito o monitoramento das metas, todavia a avaliação qualitativa não é feita de forma sistemática" (MOSSORÓ, 2011a, n.p.). Por sua vez, o PAR de Natal registra que o "[...] PME existe, necessitando que se proceda a uma revisão, inclusive, analisando aspectos além do quantitativo" (NATAL, 2011, n.p.). 
O segundo PAR de Mossoró (2011-2014) demonstra que o PME foi retomado, está sendo monitorado e cresceu a participação dos profissionais da educação nesse acompanhamento. No entanto, as duas redes de ensino apontam que a participação da sociedade civil precisa ser ampliada e que, em grande medida, o monitoramento das metas do PME ocorre com base em índices quantitativos. Isso, provavelmente, é insuficiente para a compreensão da realidade educacional do município e para subsidiar as futuras intervenções, comprometendo a eficácia das ações subsequentes.

A participação da sociedade civil na elaboração e no monitoramento dos planos governamentais vem sendo, cada vez mais, valorizada pelas políticas governamentais; no entanto, Gandin (2013) adverte que, muitas vezes, as autoridades defendem a participação, apenas, como instrumento de legitimação das ações, visto que as decisões já foram tomadas. Isso ocorreu na elaboração da proposta PAR, uma vez que a participação dos entes federados foi limitada, cabendo à esfera nacional elaborar o plano e aos municípios analisarem suas situações educacionais e definirem as ações que pretendiam executar. Embora a ação seja centralizada, o indicador referente ao Plano Municipal de Educação, a exemplo de outros, propõe estratégias para consolidar a participação de forma descentralizada, em âmbito local, visando à implementação das ações do PAR.

A participação social é essencial na avaliação do cumprimento das metas do PME porque possibilita o desenvolvimento de análises quantitativas e qualitativas da situação educacional da rede de ensino em relação às metas propostas. Assim, o município de Natal se comprometeu a formar "[...] grupos entre os membros do Conselho Municipal de Educação para criar estratégias à revisão do PME e analisar os dados atuais da Rede Municipal de Ensino verificando seus indicadores" (NATAL, 2011, n.p.).

Apesar de o PAR chamar a atenção para a importância dos dados quantitativos e qualitativos, na parte referente à demanda para a rede municipal, Mossoró tem privilegiado os dados quantitativos em detrimento dos qualitativos. $\mathrm{Na}$ demanda descrita para a rede municipal de Mossoró, registra-se: "O cumprimento do PME e a sua avaliação por meio de um sistema instituído pelo Decreto no 3.749, de 21 de março de 2011 - GP, que institui o Sistema de Avaliação da Educação Municipal - SIAVE” (MOSSORÓ, 2011b, n.p.).

Conforme o referido decreto, o SIAVE (MOSSORÓ, 2011b) se utiliza de vários procedimentos de avaliação interna e externa às instituições com o objetivo de "[...] assegurar o desempenho dos estudantes e a consequente qualidade da educação pública” (p. 2). Para tanto, propõe-se aferir o desempenho das unidades educacionais, dos órgãos de apoio à educação, da Gerência Executiva da Educação (GEED), dos estudantes, professores, supervisores, gestores e funcionários, com 
vistas a contribuir para a qualidade educacional e garantir a eficácia e efetividade da Rede. Conforme o decreto, o resultado dessa avaliação tanto será referência para progressão funcional quanto para a concessão de prêmios e liberação para capacitação profissional (MOSSORÓ, 2011b).

Esse sistema se pauta em uma visão gerencial que utiliza a avaliação como meio de controle de resultados, colocando em prática os princípios da responsabilização dos sujeitos por suas ações, instituindo a competição entre os sujeitos e a premiação dos desempenhos como meio de estimular a melhoria educacional. Conforme o PAR 2011-2014 de Mossoró o acompanhamento das metas do PME será articulado à análise dos resultados do SIAVE, configurando, assim, um indício da primazia dos dados quantitativos sobre os qualitativos.

Cary e Jany-Catrice (2015) demonstram que, na área da Avaliação de Políticas Públicas impulsionadas no contexto da Nova Gestão Pública, tem crescido a busca pela quantificação, que expressa um fenômeno sociológico central, visto que, cada vez mais, o número tem se revestido de importância. Nesse contexto, é comum o uso de indicadores sociais que informam sobre a realidade, permitindo monitorá-la e subsidiar a reformulação das políticas públicas, sendo essa a visão que prevaleceu no PAR de Mossoró.

Os dados numéricos não são neutros e precisam ser interpretados com base no cruzamento de diferentes informações que permitam identificar como as ações foram desenvolvidas, quais os sujeitos envolvidos, em que contexto e condições, entre outros elementos importantes para subsidiar o planejamento subsequente. Daí, a importância de o monitoramento do PAR recorrer a dados quantitativos e qualitativos.

É necessário lembrar que o formulário do PAR é padrão para todos os municípios, cabendo aos responsáveis pelo plano escolher a opção que mais se aproxima da sua realidade. Nesse caso, na visão de Alcântara e Barão (2014), "[...] as especificidades locais são lidas a partir de lentes externas, sob normas uniformizadoras que não contemplam necessariamente a realidade local" (p. 260). Nesse caso, no preenchimento do formulário, há pouco espaço para os responsáveis pela elaboração do PAR retratarem suas realidades bem como as concepções que norteiam a educação municipal, a exemplo do campo destinado à justificativa para o critério de pontuação atribuída ao indicador do PAR de Mossoró que demonstra que o acompanhamento do PME se dará por meio do SIAVE.

No que concerne às opções propostas pelo PAR 2011-2014, os dois municípios elegeram as seguintes subações: capacitação da equipe da secretaria estadual para atuar no acompanhamento e reformulação do plano, em parceria com representantes da sociedade civil e criação dos meios necessários à reestruturação do Plano Municipal, em 
consonância com as diretrizes do novo PNE (2014-2024), promovendo ações com vistas à sua aprovação na Câmara Municipal e à sua divulgação nas escolas para que sejam realizadas as devidas adequações em seus projetos pedagógicos (MOSSORÓ, 2011a, n.p.; NATAL, 2011 , n.p.).

As subações escolhidas contemplam os requisitos necessários à implementação de um plano, enfatizando a capacitação dos sujeitos, a participação da sociedade civil, a avaliação como base para a reestruturação do PME, sua necessária articulação com o PNE. A implementação dessas subações, apesar de trazer um formato padrão e de induzir, em certa medida, as ações em curso na esfera local, dependerá dos arranjos construídos pelos sujeitos que impulsionam suas ações a partir de concepções próprias, fazendo uso de sua autonomia relativa.

Como coroamento dos processos de monitoramento e avaliação dos Planos Municipais bem como considerando o prazo de um ano definido no PNE (2014-2024) para elaboração dos novos Planos Municipais, o Jornal Oficial de Mossoró publicou, em sua edição de 4 de agosto de 2015, a Lei no 3.298, aprovando o novo plano de educação do município, com vigência prevista para os próximos dez anos (MOSSORÓ, 2015). Referente ao município de Natal, já existe uma versão preliminar do Documento Base do Plano Municipal de Educação 2015-2025 da cidade de Natal (NATAL, 2015),mas, até fevereiro de 2016, o novo plano ainda não havia sido aprovado pela Assembleia Legislativa. Esses Planos de Educação elaborados nos municípios de Natal e Mossoró em articulação com as diretrizes do Plano Nacional de Educação induzidas pelo Plano de Ações Articuladas, podem vir a constituir-se em espaço ampliado da participação da sociedade civil e do exercício da autonomia dos municípios, visando contribuir para a constituição do SNE.

\section{CONSIDERAÇÕES FINAIS}

As políticas educacionais das últimas décadas têm procurado resgatar o papel da União enquanto coordenadora e articuladora do Sistema Nacional de Educação. Várias iniciativas foram tomadas com o objetivo de resgatar os preceitos previstos na Constituição Federal (BRASIL, 2010), para que os municípios assumissem seu papel de protagonista na implementação das políticas educacionais. Várias iniciativas foram tomadas nesse sentido, entre as quais merece destaque a aprovação do PNE 2001-2010 e do PNE 2014-2024, que procuraram realçar a importância de se estabelecer o regime de colaboração entre os entes federados, deixando explícitas suas competências e as responsabilidades referentes ao campo da educação. 
Para imprimir um caráter mais pragmático ao planejamento educacional dos municípios brasileiros e, visando a uma maior organicidade às atividades a serem financiadas e assessoradas pela União, foi instituído, no âmbito do Plano de Metas Compromisso Todos pela Educação, o Plano de Ações Articuladas. Planejamento de cunho gerencial, o PAR tem orientado as ações dos municípios, estabelecido metas e estratégias visando a uma melhor qualidade da educação. Como instrumento de planejamento, o PAR tem possibilitado uma maior relação interfederativa entre os níveis de governo, minimizando as práticas paternalistas na provisão de recursos aos estados e municípios.

Quanto à gestão educacional, o PAR procurou orientar aspectos para a consolidação da gestão democrática, estimulando, entre outras, as ações de dinamização dos Planos Municipais de Educação. Vale ressaltar que existe, no PAR, um caráter autoritário e gerencial que se observa no direcionamento das ações a serem implementadas pelos municípios. Essa característica tem reduzido o papel dos municípios na concepção e na formulação das suas políticas educacionais. As ações são definidas a priori, evidenciando que há uma imposição do governo central que demarca uma interferência na gestão municipal, fragilizando, desse modo, os mecanismos de gestão democrática, como a autonomia e a participação. Dessa forma, há uma centralização das políticas nas mãos do governo federal, permanecendo a lógica de indução à implementação de políticas mediante a concessão de financiamento e assistência técnica.

Apesar de o PAR impulsionar um processo de planejamento padronizado, que não contempla as especificidades locais, tem promovido a prática do planejamento no âmbito municipal. No caso de Mossoró e Natal, cujas redes de ensino já promoviam a prática do planejamento de médio e curto prazo, o PAR se constituiu em importante referencial para a promoção do acompanhamento e avaliação dos Planos Municipais de Educação já existentes. As avaliações realizadas no âmbito do PAR permitiram que os dois municípios identificassem os pontos fracos, conhecessem suas realidades e apontassem estratégias para subsidiar a elaboração dos novos planos municipais em articulação com as diretrizes do PNE 2014/2024, o que, certamente, poderá contribuir para a configuração do SNE.

\section{REFERÊNCIAS}

ALCÂNTARA, Alzira Batalha; BARÃO, Gilcilene de Oliveira D. Planos federais e municipais de educação: embates e contradições. In: SOUZA, Donaldo Bello de; MARTINS, Angela Maria (Orgs.). In: Planos de educação no Brasil: planejamento, políticas, práticas. São Paulo: Loyola, 2014, p. 253-275. 
BORDIGNON, Genuíno, Caminhar da educação brasileira: muitos planos, pouco planejamento. In: SOUZA, Donaldo Bello de; MARTINS, Angela Maria (orgs.). Planos de educação no Brasil: planejamento, políticas, práticas. São Paulo: Loyola, 2014, p. 29-53.

BRASIL. Lei no 13.005, de 25 de julho de 2014. Aprova o Plano Nacional de Educação. Diário Oficial da União. Brasilia: Imprensa Nacional, 2014. Disponível em: <http://www.planalto.gov.br/ccivil_03/_ato2011-2014/2014/ lei/113005.htm>. Acesso em: jan. 2016.

BRASIL, RESOLUÇÃO/CD/FNDE/ no 14, de 8 de junho de 2012. Brasília: MEC, 2012. Disponível em: <https://www.fnde.gov.br/fndelegis/ action/UrlPublicasAction.php?acao=abrirAtoPublico\&sgl_tipo=RES\&num_ ato $=00000014 \&$ seq_ato $=000 \& v 1 r \_a n o=2012 \& s g 1 \_o r g a o=C D / F N D E / M E C>$. Acesso em: jan. 2016.

BRASIL. Constituição da República Federativa do Brasil: Texto Constitucional promulgado em 5 de outubro de 1988, com alterações adotadas pelas Emendas Constitucionais n ${ }^{\circ}$ 53/06 e 59/09. Brasília: Senado Federal. Subsecretaria de Edições Técnicas, 2010, 104p.

BRASIL MINISTÉRIO DO PLANEJAMENTO, ORÇAMENTO E GESTÃO. SECRETARIA DE PLANEJAMENTO E INVESTIMENTOS ESTRATÉGICOS. Plano plurianual 2008-2011, projeto de lei. Brasília: MPOG, 2007a.

BRASIL, Decreto 6.094, de 24 de abril de 2007. Dispõe sobre a implementação do Plano de Metas Compromisso Todos pela Educação. Diário Oficial da União, 24 de abril de 2007, Brasília: Imprensa Oficial, 2007b.

BRASIL, RESOLUÇÃO/CD/FNDE/ nº 29 de 20 de junho de 2007Brasília: MEC: 2007c. Disponível em: https://www.fnde.gov.br/fndelegis/action/ UrlPublicasAction.php? acao=abrirAtoPublico\&sgl_tipo=RES\&num_ ato $=00000029 \&$ seq_ato $=000 \& v 1 r \_a n o=2007 \& s g l \_o r g a o=C D / F N D E / M E C$. Acesso em: 16. nov. 2015.

BRASIL, RESOLUÇÃO/CD/FNDE/ $\mathbf{n}^{\circ} .47$ de 20 de setembro de 2007d. Disponível em: <http://www.fnde.gov.br/fnde/legislacao/resolucoes/ item/3204-resolu \%C3\%A7\%C3\%A3o-cd-fnde-n\%C2\%BA-47-de-20-de- 
setembro-de-2007?highlight $=$ YTo0OntpOjA7czoxMToicmVzb2x1w6fDo28i O2k6MTtpOjQ3O2k6MjtpOjIwMDc7aTozO3M6NzoiNDcgMjAwNyI7fQ>. Acesso em: jan. 2016.

BRASIL. MINISTÉRIO DO PLANEJAMENTO, ORÇAMENTO E GESTÃO SECRETARIA DE PLANEJAMENTO E INVESTIMENTOS ESTRATÉGICOS. Plano Plurianual 2004-2007. Mensagem Presidencial. Brasília: MPOG, 2003.

BRASIL, Lei 10.172, de 9 de janeiro de 2001. Aprova o Plano Nacional de Educação e dá outras providências. Diário Oficial da União. Brasília: Imprensa Nacional, 2001.

CABRAL NETO, Antônio. Plano nacional e sistema nacional de educação: a difícil tarefa de conceber uma política de estado. In: FRANÇA, Magna; MOMO, Mariangela (Orgs.). Processo democrático participativo: a construção do PNE. Mercado de Letras: São Paulo, 2014, p. 43-76.

CARDOSO JR, José Celso. Planejamento governamental e gestão pública no Brasil: elementos para ressignificar o debate e capacitar o estado. Texto para Discussão. Brasília, 2011. Disponível em: <http://www.ipea.gov.br/ouvidoria>. Acesso em: 24 de janeiro de 2016.

CARY, Paul; JANY-CATRICE, Florence. Novos indicadores de riqueza: avaliar o que e para quem? In: ARCOVERDE, Ana Cristina Brito. Avaliação de políticas públicas no capitalismo globalizado: para que e para quem? Recife: UFPE, 2015. p. 120-141.

CURY, Jamil Carlos Roberto. Apontamentos de palestra proferida na Conferência Livre promovida pela Anped, CNTE, UNE, CUT, Contee. Belo Horizonte, maio de 2013. Disponível em: <http// www.anped.org.br>. Acesso em: jan. 2016.

FONSECA, Marília. O projeto político-pedagógico e o plano de desenvolvimento da escola: duas concepções antagônicas de gestão escolar. Cad. Cedes, Campinas, v. 23, n. 61, p. 302-318, dezembro 2003. Disponível em http://www.scielo.br/ pdf/ccedes/v23n61/a04v2361.pdf. Acesso em 20 de janeiro de 2016. 
GANDIN, Danilo. Soluções de planejamento para uma prática estratégica e participativa. Petrópolis, RJ: Vozes, 2013.

IBGE. Censo Demográfico 2010. Disponível em: <http://www.ibge.gov.br/ home/estatistica/populacao/censo2010/>. Acesso em: 25 set. 2016. - VEJA QUE JÁ ESTÁ NA REFRÊNCIA

IBGE. Perfil dos municípios brasileiros 2009. Disponível em: http://www.ibge. gov.br/home/estatistica/economia/perfilmunic/2009/>. Acesso em: 25 de jan. 2016 - VEJA QUE JÁ ESTÁ NA REFRÊNCIA

IBGE. Perfil dos municípios brasileiros 2011. Ministério do Planejamento, orçamento e gestão. Rio de Janeiro:Instituto Brasileiro de Geografia e Estatística, 2012.

MEC/SASE. Diretoria de Articulação com os Sistemas de Ensino. Instituir um Sistema Nacional de Educação: agenda obrigatória para o país. Brasília: MEC, 2015. Disponível em: <http://pne.mec.gov.br/images/pdf/SNE_junho_2015. pdf>. Acesso em: jan. 2016.

MOSSORÓ (Cidade), Lei no 3.298, de 04 de agosto de 2015. Aprova o Plano Municipal de Educação do Município de Mossoró, de duração decenal e dá outras providências. Jornal Oficial de Mossoró, 04/0802015,Mossoró-RN: 2015.

MOSSORÓ (Cidade), Sistema Integrado de Ministério da Educação/ SE PAR analítico do Município de Mossoró - RN (2011-2014). Natal: SIME, 2011a.

MOSSORÓ (Cidade), Decreto 3.749, de 21 de março de 2011. Institui o Sistema de Avaliação da Educação Municipal - SIAVE e dá outras providências. Jornal Oficial de Mossoró, Mossoró-RN, 25 mar. 2011b.

MOSSORÓ (Cidade), PAR analítico do Município de Mossoró - RN (20072011). SIMEC - Sistema Integrado de Ministério da Educação/ SE - Secretaria Executiva. 2007.

MOSSORÓ (Cidade). Plano Municipal de Educação: 2004/2013. Mossoró, RN: Prefeitura Municipal. Gerência Executiva de Educação e do Desporto, 2004. 
NATAL, Secretaria Municipal de Educação de Natal. Documento Base Plano Municipal de Educação 2015-2025. Natal, RN: SMEN: 2015. Disponível em: <https://natal.rn.gov.br/sme/.../DOCUMENTO_BASE_DO_PMENATAL_2015-2025.pdf>. Acesso em: 16 fev. 2016.

NATAL, Secretaria Municipal de Educação de Natal. Plano Municipal de Educação (2005-2014). Natal, RN: SMEN: 2005.

NATAL, Sistema Integrado de Ministério da Educação/ SE.PAR analítico do Município de Natal -RN (2007-2011). Natal: SIMEC-Secretaria Executiva, 2007.

NATALSistema Integrado de Ministério da Educação/ SE, PAR analítico do Município de Natal-RN (2011-2014). Natal: SIMEC- Secretaria Executiva. 2011.

PNUD/BRASIL. Atlas do desenvolvimento Humano no Brasil 2013. Disponível em: <http://atlasbrasil.org.br/2013/perfil/mossoro_ rn\#demografia >. Acesso em: 29 jul. 2013.

SAVIANI, Demerval. Plano Nacional de Educação, a questão federativa e os municípios: o regime de colaboração e as perspectivas da educação brasileira. São Paulo: Grabois, 2011.

SAVIANI, Dermeval. O Plano de Desenvolvimento da Educação: análise do projeto do MEC. Educação e Sociedade, v. 28, n. 100, out. 2007.

SAVIANI, Dermeval. Sistema Nacional de Educação articulado ao Plano Nacional de Educação. Revista Brasileira de Educação. v. 5, n. 44,p. 380 a 412, mai/ago., 2010.

ANTÔNIO CABRAL NETO possui graduação em Pedagogia pela Universidade Federal do Rio Grande do Norte (1978), mestrado em Educação pela Universidade Federal do Rio de Janeiro (1980) e doutorado em Educação pela Universidade de São Paulo (1995). Atualmente é professor da Universidade Federal do Rio Grande do Norte. Tem experiência na área de Educação, com ênfase em Educação, atuando principalmente nos seguintes temas: descentralização, política educacional, gestão educacional, financiamento e ensino fundamental. Foi pró-reitor de graduação da Universidade Federal do Rio Grande do Norte, no período de 2003-2007. Atualmente é vice-presidente da Associação Nacional de Pós-Graduação e Pesquisa em Educação. E-mail: acabraln@yahoo.com.br 
ALDA MARIA DUARTE ARAUJO CASTRO possui graduação em Pedagogia pela Universidade Federal de Sergipe (1977), mestrado em Educação pela Universidade Federal do Rio Grande do Norte (1998) e doutorado em Educação pela Universidade Federal do Rio Grande do Norte (2001). Atualmente é professor adjunto da Universidade Federal do Rio Grande do Norte. Tem experiência na área de Educação, com ênfase em Política Educacional, atuando principalmente nos seguintes temas: políticas de formação de professores, educação a distância e da educação superior. Atualmente exerce a função de Coordenadora do Programa de Pós-graduação em Educação da Universidade Federal do Rio Grande do Norte. E-mail: aldacastro01@hotmail.com

LUCIANE TERRA DOS SANTOS GARCIA possui graduação em Pedagogia pela Universidade do Estado do Rio de Janeiro, mestrado em Educação pela Universidade Federal do Rio Grande do Norte e doutorado em Educação pela Universidade Federal do Rio Grande do Norte. Atualmente é Professora da Universidade Federal do Rio Grande do Norte. Tem experiência na área de Educação, com ênfase em política educacional, atuando principalmente nos seguintes temas: gestão educacional, cultura organizacional, projeto políticopedagógico e avaliação institucional. E-mail: ltsgarcia@gmail.com

Recebido em fevereiro de 2016 Aprovado em abril de 2016 